\title{
Locally Delivered Tetracycline Fibres in the Treatment of Chronic Periodontitis
}

\author{
Dr. Shristi Kafle, ${ }^{1}$ Dr. Shaili Pradhan, ${ }^{2}$ Dr. Sujaya Gupta ${ }^{3}$ \\ ${ }^{1}$ Department of Periodontology and Oral Implantology, Chitwan Medical College and Teaching Hospital, Bharatpur, Nepal; \\ ${ }^{2}$ Periodontology and Oral Implantology Unit, Dental Department, National Academy of Medical Sciences, Bir Hospital, Kathmandu, Nepal; \\ ${ }^{3}$ Department of Periodontics, Kantipur Dental College, Kathmandu, Nepal.
}

\begin{abstract}
Background: Chronic periodontitis is a highly prevalent and recurrent form of periodontal disease and locally delivered tetracycline fibres are considered to exert tremendous benefits for its treatment.

Aim: The aim of the study was to observe the clinical results of locally delivered tetracycline fibres in the treatment of chronic periodontitis Materials and Methods: Patients aged 35-54 years diagnosed with chronic periodontitis of both gender fulfilling the inclusion criteria were selected. A sample size of 30 was calculated and total number of 60 posterior sites were selected. These sites were divided into two sets in a split mouth design as control sites treated with SRP alone and test sites treated with SRP plus tetracycline fibres.

Results: A combination of scaling, root planing and local drug delivery in the form of tetracycline fibres resulted in added benefits in the control of chronic periodontitis on the basis of the clinical findings from this study.

Conclusion: This study further adds to the evidence that tetracycline fibres as locally delivered agent are safe and effective adjunct to scaling and root planing, and can produce significant clinical benefits when compared to scaling and root planing alone in the treatment of chronic periodontitis.

Keywords: Chronic periodontitis; local drug delivery; tetracycline.
\end{abstract}

\section{INTRODUCTION}

Chronic periodontitis is an infectious disease resulting from inflammation within the supporting tissues of the teeth characterised by progressive attachment and bone loss. ${ }^{1}$ It is the most common form of periodontitis which is associated with an accumulation of plaque and calculus with slow to moderate rates of disease progression. ${ }^{2}$ There is growing interest in localised antimicrobial therapy because of the site-specific nature of periodontal infections, greater subgingival concentrations of antimicrobial agent, and reduced side-effects compared to systemic antibiotics. ${ }^{3}$

The periodic use of local drug delivery helps to minimise bleeding and stabilise attachment levels, thereby reducing probing pocket depth. Thus, it appears to hold sound promise in periodontal therapy allowing better control

\section{Correspondence:}

Dr. Shristi Kafle

Department of Periodontology and Oral Implantology, Chitwan Medical College and Teaching Hospital, Bharatpur, Nepal. email: kafle.shristi@gmail.com

\section{Citation}

Kafle S, Pradhan S, Gupta S. Locally Delivered Tetracycline Fibres in the Treatment of Chronic Periodontitis. J Nepal Soc Perio Oral Implantol. 2018;2(2):45-8. and management of periodontal diseases. Various locally delivered chemotherapeutic agents available are: tetracycline fibres (Actisite), metronidazole gel (Elyzol), minocycline gel and minocycline microspheres (Arestin), chlorhexidine chip (Perio Chip) and doxycycline hyclate (Atridox) to name a few. ${ }^{4}$

Tetracycline group is among the most widely used drugs to treat periodontal diseases. Factors that may play a role in the efficacy of tetracyclines in the subgingival area include substantivity, whereby tetracycline strongly adsorbs to and then is released from tooth surfaces while retaining its antimicrobial activity. ${ }^{5}$ This study was performed with an aim to evaluate the efficacy of locally delivered tetracycline fibres in the treatment of chronic periodontitis.

\section{MATERIALS AND METHODS}

A non-randomised clinical trial with split mouth study design was used for the study. A total number of 30 subjects aged 35-54 years diagnosed with chronic periodontitis of both gender and able to follow verbal or written oral hygiene instructions were selected by convenience sampling technique from the Periodontology and Oral Implantology Unit, Dental Department, National Academy of Medical Sciences (NAMS), Bir Hospital. 


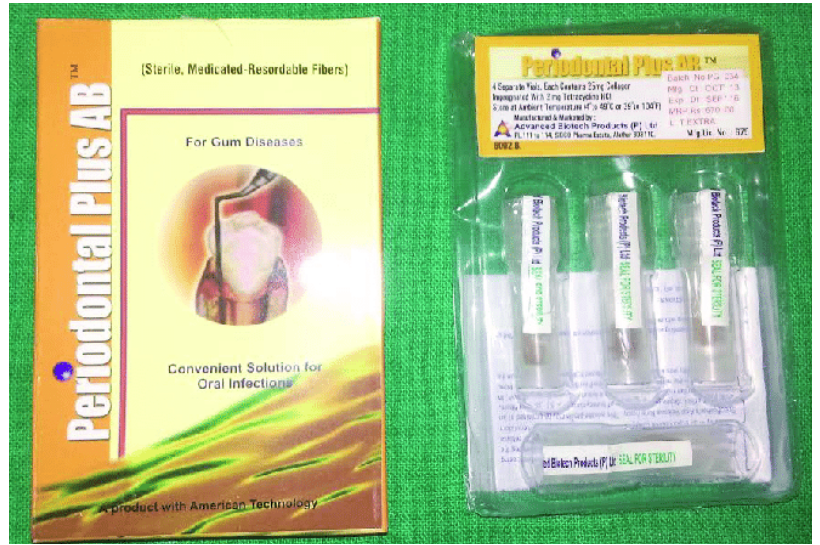

Figure 1 : Tetracycline fibres (PerioPlus $\mathrm{AB}^{\mathrm{TM}}$ ).

Among them, patients with similar probing pocket depth ranging from 5 to $8 \mathrm{~mm}$ in two contralateral sides and those fulfilling all the inclusion criteria were enrolled for the study. The participants were assigned into two sites i.e; control site [with scaling and root planing (SRP) alone] and test sites (SRP along with locally delivered tetracycline fibres). All subjects underwent periodontal examination by a single examiner. Probing pocket depth was recorded using an acrylic stent for the standardisation of readings. Periodontal parameters: plaque index (PI), gingival index (GI), and clinical attachment level (CAL) were also assessed and compared between control and test sites at baseline, two months and three months follow-up visits.

Before embarking upon the study, ethical clearance was obtained from the Institutional Review Board, NAMS, Bir Hospital. Patient attending the dental department of Bir Hospital who consented to be part of the study were selected. Written informed consent was obtained from each participant of the study who voluntarily agreed. All the expenses were borne by the principal investigator. Armamentarium used were: mouth mirror, tweezers, University of North Carolina (UNC) \#15 periodontal probe, ultrasonic scaler set, and Gracey curettes (Hu-Friedy).

Tetracycline fibres available as $2 \mathrm{mg}$ of tetracycline impregnated in $25 \mathrm{mg}$ of collagen fibres (PerioPlus $\mathrm{AB}^{\mathrm{TM}}$, Advanced Biotech Products, Chennai, India) was used.

\section{RESULTS}

Results of the study are summarised in Table 1 to 4 which show the mean scores of various periodontal parameters between control and test sites.

Table 1 compares the mean plaque scores at different time intervals i.e. at baseline, at two months and three months follow-up visits. The comparison of mean difference shows that there was no statistically significant difference in plaque scores at test and control sites at the baseline as well as during follow-up visits.

The mean gingival scores reduced from baseline at subsequent follow-up visits at both control and test sites. However, comparison between two sites did not reveal any statistically significant difference highlighting that local delivery of tetracycline fibres along with SRP does not produce significant reduction in gingival index scores compared to SRP alone (Table 2).

As depicted in Table 3, pocket depth was same in both the study sites at baseline. Following treatment with SRP alone and SRP with tetracycline fibres, there was reduction in

Table 1: Mean plaque scores at control and test sites $(n=60)$.

\begin{tabular}{|c|c|c|c|c|c|c|}
\hline \multirow{2}{*}{ Time line } & \multirow{2}{*}{$\begin{array}{c}\text { Control sites } \\
\text { (mean } \pm \text { SD) }\end{array}$} & \multirow{2}{*}{$\begin{array}{c}\text { Test sites } \\
(\text { mean } \pm \text { SD) }\end{array}$} & \multirow{2}{*}{ Mean Diff. } & \multicolumn{2}{|c|}{ 95\% CI } & \multirow{2}{*}{ P-value } \\
\hline & & & & Lower & Upper & \\
\hline At baseline & $1.831 \pm 0.32$ & $1.757 \pm 0.30$ & 0.073 & -0.091 & 0.238 & 0.378 \\
\hline At 2 months & $1.402 \pm 0.53$ & $1.281 \pm 0.52$ & 0.121 & 0.137 & -0.153 & 0.381 \\
\hline At 3 months & $1.196 \pm 0.33$ & $1.101 \pm 0.39$ & 0.095 & 0.094 & -0.093 & 0.317 \\
\hline
\end{tabular}

Table 2: Mean gingival scores at control and test sites $(n=60)$.

\begin{tabular}{|c|c|c|c|c|c|c|}
\hline & \multirow{2}{*}{$\begin{array}{l}\text { Control sites } \\
\text { (mean } \pm \text { SD) }\end{array}$} & \multirow{2}{*}{$\begin{array}{c}\text { Test sites } \\
(\text { mean } \pm \text { SD) }\end{array}$} & \multirow{2}{*}{ Mean Diff. } & \multicolumn{2}{|c|}{$95 \% \mathrm{CI}$} & \multirow{2}{*}{ P-value } \\
\hline & & & & Lower & Upper & \\
\hline At baseline & $1.885 \pm 0.440$ & $1.841 \pm 0.45$ & 0.044 & -0.186 & 0.274 & 0.704 \\
\hline At 2 months & $1.457 \pm 0.410$ & $1.410 \pm 0.40$ & 0.047 & -0.164 & 0.258 & 0.658 \\
\hline At 3 months & $1.150 \pm 0.45$ & $1.089 \pm 0.47$ & 0.060 & -0.179 & 0.300 & 0.617 \\
\hline
\end{tabular}

Table 3: Probing pocket depth (in $\mathrm{mm}$ ) at control and test sites $(\mathrm{n}=60)$.

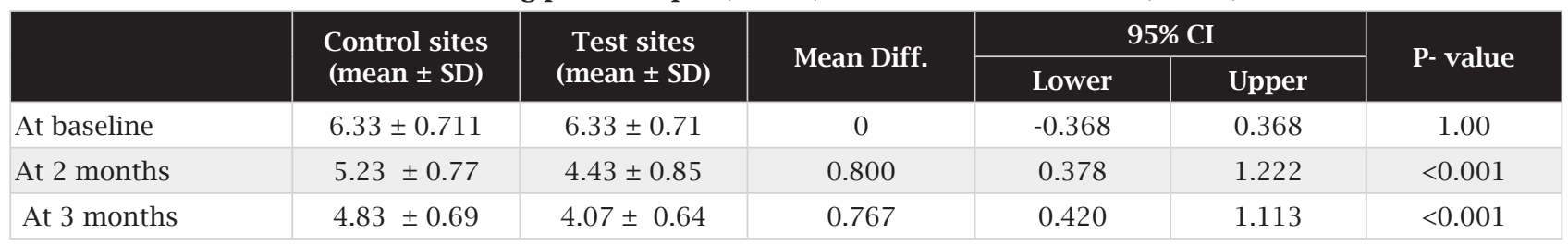


Table 4: Clinical attachment level at control and test sites $(n=60)$.

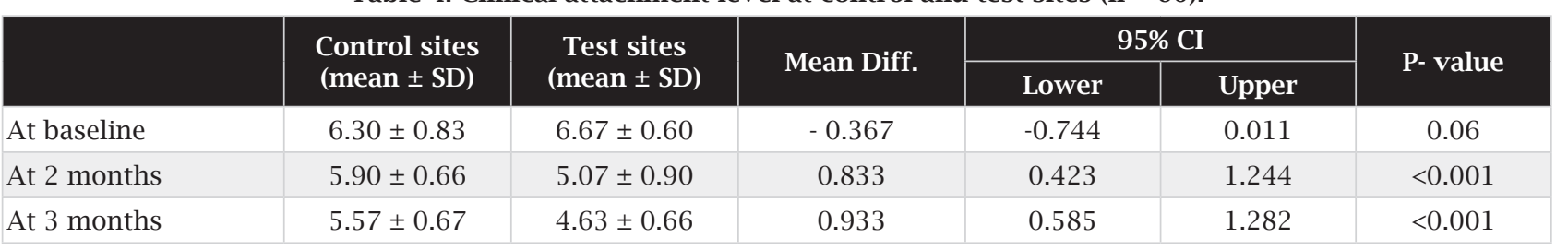

pocket depth. However, this reduction was significantly higher ( $\mathrm{p}$ value $<0.001$ ) at test sites compared to control sites.

The CAL scores at control and test sites were not significantly different at the baseline level $(\mathrm{p}$ value $=0.06$ ). However, in the follow-up visits at 2 and 3 months, the reduction in CAL was significantly higher at test sites $(\mathrm{P}<0.001)$. This indicates that efficacy of locally delivered tetracycline fibres and SRP is more compared to SRP alone in reduction of clinical attachment loss in patients suffering from chronic periodontitis.

\section{DISCUSSION}

The localised therapeutic intervention provides long-term retention of highly concentrated drug within target tissue after local delivery. It produces constant and prolonged concentration of the agent in local area. Potential therapeutic advantages of local drug delivery approach have been claimed to be several fold.

Tetracycline fibre first introduced into clinical practice in 1970s are bacteriostatic in action and hence are effective against rapidly multiplying bacteria. The proven efficacy of this group of drugs in the management of periodontal disease may be related not only to their antibacterial action but to a number of additional benefits that have been recently identified. These include collagenase inhibition, anti-inflammatory actions, inhibition of bone resorption and their ability to promote the attachment of fibroblasts to root surfaces. Consequently, tetracyclines have also been used as an adjunct to bone grafting in periodontal defects, and as agents for conditioning root surfaces to enhance the regeneration of periodontal tissues. ${ }^{6}$

In the present study, there was higher percentage reduction in plaque scores at test sites compared to control sites during the subsequent follow-up visits. These results are in accordance with the results of the studies conducted by Lindhe et $\mathrm{al}^{7}$ and Friesen et $\mathrm{al}^{8}$ who also found lower level of PI scores in their study compared to baseline. This could also be due to a greater attention to oral hygiene practice by all selected participants throughout the study.

Similarly, GI also showed significant reduction in scores from baseline to three months for both treatment groups as observed by Goodson et $\mathrm{al}^{9}$ and Minabe et al. ${ }^{10}$ Radvar et $\mathrm{al}^{11}$ found $80 \%$ reduction in sites that bled on probing during the course of their study. Adjunctive fibre therapy was significantly better in reducing GI than SRP alone at one, three, and six months as observed by Newman et al. ${ }^{12}$ Flemmig et $\mathrm{al}^{13}$ also found significantly lower scores for GI at six months.

In the present study, intra-group observation showed highly significant $(\mathrm{P}<0.001)$ reduction in probing pocket depth from baseline to three months in both groups in consistent with the study conducted by Vandekerckhove et $\mathrm{al},{ }^{14}$ Kinane et $\mathrm{al},{ }^{15}$ and Gonçalves et al. ${ }^{16}$ Current study was in accordance with Vandekerckhove et $\mathrm{al}^{14}$ where an analysed data from all sites indicated significant decrease in probing pocket depth.

A significant gain in clinical attachment level was also obtained from baseline to three months in both the treated sites $(\mathrm{P}<0.001)$, differences observed were similar to that of Goodson et al, ${ }^{9}$ Minabe et al, ${ }^{10}$ Newman et al, ${ }^{12}$ and Radvar et al. ${ }^{11}$ Minabe et $\mathrm{al}^{10}$ found gain of clinical attachment level of around $2 \mathrm{~mm}$ and suggested that the local application of antibiotic using local drug delivery in combination with root debridement may contribute to gain in clinical attachment level.

Gain in clinical attachment level were more in test than in control group as reported by Sinha et al, ${ }^{17}$ similar to present study. Gain in clinical attachment level could be attributed to anti-collagenolytic property of tetracyclines and an enhancement of collagen synthesis and their ability to promote an attachment of fibroblasts to root surfaces. ${ }^{18-22}$

Tonetti et $\mathrm{al}^{23}$ reviewed the development over the last 20 years of the evidence supporting clinical application of controlled delivery device for the treatment of human periodontitis. The study concluded that combination of tetracycline fibres with mechanical debridement represents a documented treatment alternative, the application of which may offer clinical benefits to many patients which was in accordance to the findings of present study.

\section{CONCLUSION}

Within the limits of this study, this study further adds to the evidence that tetracycline fibres as locally delivered agent are safe and effective adjunct to scaling and root planing, 
and can produce significant clinical benefits compared to scaling and root planing alone for the treatment of chronic periodontitis.

Though the local drug delivery system used in the study is safe and effective treatment modality, further longitudinal studies utilising larger sample size and even encompassing the analysis of microbiological and radiographic parameters are recommended for supporting the findings of this study.

\section{ACKNOWLEDGEMENT}

We would like to acknowledge Dr. Ranjita Shrestha Gorkhali for her valuable suggestions during the course of study.

\section{REFERENCES}

1. $\quad$ Darveau PR, Tanner A, Page RC. The microbial challenge in periodontitis. Periodontol 2000. 1997 Jun;14:12-32.

2. Listgarten MA. The role of dental plaque in gingivitis and periodontitis. J Clin Periodontol. 1988 Sep;15(8):485-7.

3. Okuda K, Wolff L, Oliver R, Osborn J, Stoltenberg L, Bereuter J, et al. Minocycline slow-release formulation effect on subgingival bacteria. J Periodontol. 1992 Feb;63(2):73-9.

4. Bonito AJ, Lux L, Lohr KN. Impact of local adjuncts to scaling and root planing in periodontal disease therapy: A systematic review. J Periodontol. 2005 Aug;76(8):1227-36.

5. Stabholz A, Kettering J, Aprecio R, Zimmerman G, Baker PJ, Wikesjo UM. Retention of antimicrobial activity by human root surfaces after in situ subgingival irrigation with tetracycline HCl or chlorhexidine. J Periodontol. 1993 Feb;64(2):137-41.

6. Goodson JM, Offenbacher S, Farr DH, Hogan PE. Periodontal disease treatment by local drug delivery. J Periodontol. 1985 May;56(5):26572.

7. Lindhe J, Heijl L, Goodson JM, Socransky SS. Local tetracycline delivery using hollow fiber devices in periodontal therapy. J Clin Periodontol. 1979 Jun;6 (3):141-9.

8. Friesen LR, Williams KB, Krause LS, Killoy WJ. Controlled local delivery of tetracycline with polymer strips in the treatment of periodontitis. J Periodontol. 2002 Jan;73(1):13-9.

9. Goodson JM, Cugini MA, Dent RL. Multi-center evaluation of tetracycline fiber therapy: II. Clinical response. J Periodontal Res. 1991 Jul;26(4):371-9.

10. Minabe M, Takeuchi K, Nishimura T, Hori T, Umemoto T. Therapeutic effects of combined treatment using tetracycline-immobilized collagen film and root planing in periodontal furcation pockets. J Clin Periodontol. 1991 May;18(5):287-90.

11. Radvar M, Pourtaghi N, Kinane DF. Comparison of 3 periodontal local antibiotic therapies in persistent periodontal pockets. J Periodontol. 1996 Sep;67(9):860-5.

12. Newman MG, Kornman KS, Doherty FM. A 6-month multi-center evaluation of adjunctive tetracycline fiber therapy used in conjunction with scaling and root planing in maintenance patients: clinical results. J Periodontol. 1994 Jul;65(7):685-91.

13. Flemmig TF, Weinacht S, Rudiger S, Rumetsch M, Jung A, Klaiber B. Adjunctive controlled topical application of tetracycline HCl in the treatment of localized persistent or recurrent periodontitis. Effects on clinical parameters and elastase-alpha1-proteinase inhibitor in gingival crevicular fluid. J Clin Periodontol. 1996 Oct;23(10):914-21.

14. Vandekerckhove BN, Quirynen M, van Steenberghe D. The use of tetracycline-containing controlled release fibers in the treatment of refractory periodontitis. J Periodontol. 1997;68:353-61.

15. Kinane DF, Radvar M. A six-month comparison of three periodontal local antimicrobial therapies in persistent periodontal pockets. J Periodontol. 1999 Jan;70(1):1-7.

16. Gonçalves C, Rodrigues RMJ, Feres-Filho EJ, Colombo AP. Clinical effects of systemic and topical tetracycline therapy on chronic periodontal disease. Braz J Oral Sci. 2004 Jan-Mar;3(8):384-9.

17. Sinha S, Kumar S, Dagli N, Dagli RJ. Effect of tetracycline HCl in the treatment of chronic periodontitis - A clinical study. J Int Soc Prev Community Dent. 2014 Sep;4(3):149-53.

18. Mehta DS, Mohammadi N. A comparative assessment of the efficacy of tetracycline fibre therapy and phase I therapy in the treatment of chronic adult periodontitis. J Indian Dent Assoc. 2000;71:207-11.

19. Maiden MF, Tanner A, McArdle S, Najpauer K, Goodson JM. Tetracycline fiber therapy monitored by DNA probe and cultural methods. J Periodontal Res. 1991 Sep;26(5):452-9.

20. Golub LM, Ramamurthy N, McNamara TF, Gomes B, Wolff M, Casino A, et al. Tetracyclines inhibit tissue collagenase activity. A new mechanism in the treatment of periodontal disease. J Periodontal Res. 1984 Nov;19(6):651-5.

21. Yanagimura M, Koike F, Hara K. Collagenase activity in gingival crevicular fluid and inhibition by tetracyclines. J Dent Res. 1989;68(Spec Iss):1691-3.

22. Golub LM, Ramamurthy NS, McNamara TF, Greenwald RA, Rifkin BR. Tetracyclines inhibit connective tissue breakdown: new therapeutic implications for an old family of drugs. Crit Rev Oral Biol Med. 1991;2(3):297-321.

23. Tonetti MS. Local delivery of tetracycline: from concept to clinical application. J Clin Periodontol. 1998 Nov;25(11 Pt 2):969-77. 